\title{
STUDY ON CONCENTRATIONS OF ACIDS AND ALCOHOLS EMITTED BY PINUS RADIATA DURING HIGH-TEMPERATURE DRYING
}

\author{
Jiangyi $\mathrm{Chu}^{1}$, Jinghui Jiang ${ }^{1}$, Chusheng $\mathrm{Q}^{2}$, Yongdong Zhou ${ }^{1}$ \\ ${ }^{1}$ Chinese Academy Of Forestry \\ China \\ ${ }^{2}$ Beijing Forestry University \\ China
}

(Received September 2020)

\begin{abstract}
The purpose of this paper is to investigate the influence of kiln temperature, relative humidity and wood moisture content on the content of acid and alcohol released in the drying process of high temperature kiln by studying the radiated pine sawn timber of $40 \mathrm{~mm}$ thickness. The drying temperature was between $101^{\circ} \mathrm{C}$ and $115^{\circ} \mathrm{C}$, the relative humidity in the drying kiln was reduced from $86.1 \%$ to $39.6 \%$, the moisture content of the lumber was reduced from $106.16 \%$ to $11.98 \%$, and gas extraction was executed nine times with an extraction speed of $1.0 \mathrm{~L} \cdot \mathrm{min}^{-1}$ and a sampling time of $30 \mathrm{~min}$. The concentrations of acids and alcohols were analyzed by HPLC. The results showed that the concentrations of formic acid, acetic acid, and methanol emitted in the kiln during drying were 215.6-748.2, 4148.8-16803.2, and $6381.9-15648.9 \mathrm{mg} \cdot \mathrm{m}^{-3}$, respectively, and these concentrations were significantly higher than the relevant standards. The concentrations of the emitted formic acid and acetic acid were proportional to the drying temperature, the concentrations of the emitted formic acid and acetic acid were inversely proportional to the relative humidity in the kiln and the moisture content of the lumber. The concentration of the emitted methanol was independent of the drying temperature, relative humidity in the kiln, and moisture content of the lumber. It is therefore suggested that formic acid, acetic acid, and methanol be separately recovered during the high-temperature drying of Pinus radiata lumber.
\end{abstract}

KEYWORDS: Lumber, Pinus radiata, high-temperature drying, emission of acid and methanol, relative humidity, moisture content. 


\section{INTRODUCTION}

High-temperature drying is defined as an artificial drying process during which the temperature of the drying medium (wet air, superheated steam) is $100-140^{\circ} \mathrm{C}$ (Zhou and $\mathrm{Li}$ 2005). During this process, large amounts of volatile organic compounds (VOCs) such as aldehydes, acid alcohols, and terpenes are emitted (Long and Lu 2008). VOCs refer to compounds that contain carbon and are involved in atmospheric photochemical reactions, excluding $\mathrm{CO}, \mathrm{CO}_{2}$ and other compounds specified in the federal regulations (Milota 2000). VOC volatilization is affected by tree species, wood structure, drying medium temperature and humidity and moisture content (Shmulsky 2000). VOC in wood drying can be divided into two categories. One is terpene and terpene compounds, and the other is non-terpene volatile compounds, mostly organic acids such as formic acid, acetic acid and propionic acid (Lavery 1998). VOC in wood drying comes from some volatile components in wood itself - extractions. Studies showed that the volatiles of pine wood during drying accounted for $25 \%$ to $50 \%$ of the total extract content in the wood, while the volatiles of spruce accounted for 10\% - 50\% (Englund and Nussbaum 2000). The aldehydes released by wood mainly come from the oxidative decomposition of unsaturated fatty acids (Makowski et al. 2005, Back and Allan 2000). Softwoods emit the highest concentrations of wood VOCs. The main emission from softwood is terpenes (Risholm-Sundman et al. 1998, Pohleven. et al. 2019). According to China's emission standard of air pollution (GB 16297: 1996) and the design specifications of the environmental protection of wood-based panel engineering, (GB/T 50887: 2013) the monitored concentration limits of formaldehyde and formic acid emissions without organization are 0.25 and $0.20 \mathrm{mg} \cdot \mathrm{m}^{-3}$, respectively. Terpene compounds can react with nitrogen oxides under ultraviolet light, resulting in ozone and other photochemical oxides (Risholm-Sundman et al. 1998) that will generate photochemical smog, thus affecting human health and the environment (Long 2012). The concentration limit of terpene suggested by the German committee for health-related evaluation of building products is $1.5 \mathrm{mg} \cdot \mathrm{m}^{-3}$ (Däumling et al. 2005). However, although they are also hazards to the environment and human health, little attention has been paid to acids and alcohols in VOCs emitted during drying. Acid, water or methanol, ketone, ether, carbon dioxide and aromatics are the main gaseous products during wood drying (He et al. 2019). Among these polar volatiles, methanol vapor has a strong stimulating effect on the respiratory tract mucosa and can cause dizziness, headache, fatigue, insomnia, and turbidity of consciousness. Formic acid is six times as harmful as methanol, and formaldehyde is 30 times as harmful as methanol. Acetic acid is irritating to the nose, eyes, and respiratory tract. Sometimes the components of volatile organic wood can interact with each other under certain conditions and form secondary pollutants, thus affecting human health and ecological environment (Granstrom 2003). VOCs detection methods often used in wood drying process include: direct measurement method, weighing method and condensation impact method (Tong 2009). At present, the commonly used measurement method is US EPA method 25A, which belongs to the direct measurement method (Wu et al. 1999). In addition, it is an indirect measurement method, which is expressed by the VOC difference of the sample before and after drying. This method is widely used in large commercial drying kilns (Dallons et al. 1993). Standards have been established to determine the limits of the average concentrations and restrictions for short-term exposure to methanol, formic acid, and acetic acid in the air and in the workplace. Examples include the "Occupational exposure limits for hazardous factors in the workplace, part 1: Chemical hazardous factors" (GBZ 2.1-2019, National Standards of China), the Workplace Exposure Standard (New Zealand 2001), Occupational Safety and Health Regulations (OSHA, USA), and the Technical regulations on hazardous substances 
(TRGS 900, 2011). However, few studies in this field have been reported. During the drying of Cunninghamia lanceolat at a constant temperature of $120^{\circ} \mathrm{C}$, the concentrations of formic acid and acetic acid emissions are higher than the limits set by China's standards (Long et al. 2007).

Acetaldehyde is a carcinogen that irritates human skin and mucous membranes (IARC 1999). Similarly, during the drying of Eucalyptus urophylla at 90 and $120^{\circ} \mathrm{C}$, the concentrations of formic acid, acetic acid, and methanol emissions exceed the limits set by China's standards; the concentration of methanol emissions even exceeds the maximum allowable emission concentration in China's "Comprehensive emission standards for air pollutants. " Drying is executed at constant temperatures, and the concentrations of formic acid, acetic acid, and methanol emitted by sawn wood are dependent on the tree species. The release of high concentration acid is also related to high mass loss, large mechanical property loss, low luminosity and low hue (Bror 2004). Therefore, it is necessary to investigate the concentrations of formic acid, acetic acid, and methanol emitted during the high-temperature drying of sawn timber to provide references for the recovery of drying exhaust at different stages.

In this study, Pinus Norway lumber was selected as the research object; it was dried by a high-temperature drying process, and the exhaust was collected at different stages to investigate the effects of the drying stage, temperature, moisture content of the sawn timber, and other factors on the concentrations of formic acid, acetic acid, and methanol in the exhaust.

\section{MATERIAL AND METHODS}

\section{Materials and drying experiments}

Pinus Norway lumber was obtained from New Zealand and cut into 36 samples of $900 \times 120 \times 40 \mathrm{~mm}(\mathrm{~L} \times \mathrm{W} \times \mathrm{T})$ in size. The initial moisture content of the samples was $106.16 \%$, and the samples were dried until the moisture content reached $12 \%$, as presented in Fig. 1.

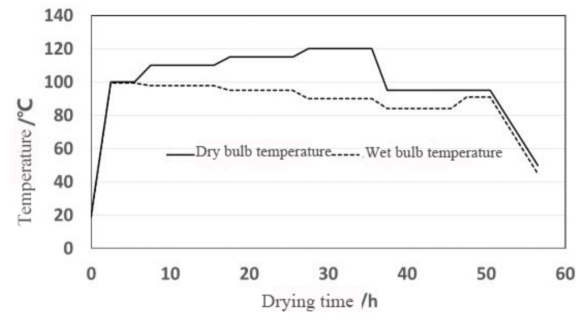

Fig. 1: Schedule of high-temperature drying.

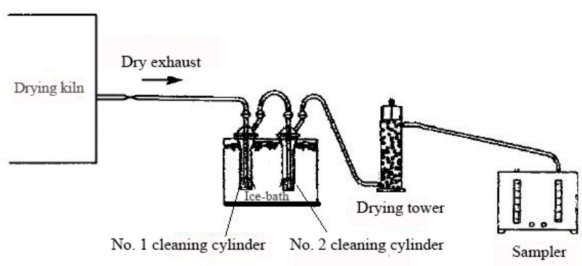

Fig. 2: Diagram of acid and methanol collection during lumber drying. 


\section{Collecting acid and methanol}

Organic volatiles of acids and alcohols were collected via an ice water bath; $40 \mathrm{~mL}$ of distilled water was injected into two $200 \mathrm{~mL}$ gas bottles, which were connected and placed in an ice tank to fully dissolve the acids and alcohols. A dryer and sampler were then connected, as illustrated in Fig. 2. The temperature detection hole of the drying kiln was employed as the sampling hole, and a double-channel sample collector was used to collect the VOCs generated at nine sampling times during drying. During sampling, the temperature and humidity in the kiln were stable, the sampling rate was $1.0 \mathrm{~L} \cdot \mathrm{min}^{-1}$, and the sampling time was $30 \mathrm{~min}$. The concentrations of formic acid, acetic acid, and methanol in the gas bottles were analyzed by high-performance liquid chromatography (HPLC). The amounts of acids and alcohols emitted were then calculated according to the volume of liquid in the cylinder. The total volume of collected gas was the sum of the volume of gas converted from the liquid increment in the cylinder under the kiln conditions at that time and $30.0 \mathrm{~L}$ of gas collected by the sample collector. The concentrations of acids and alcohols in the kiln were calculated according to the amounts of acids and alcohols emitted and the total volume of collected gas. After each sampling cycle, the moisture content testing board was removed from the kiln and the moisture content of the sawn timber was measured. The results are summarized in Tab. 1.

Tab. 1: Dry-bulb and wet-bulb temperatures, relative humidity in the kiln, and moisture content of the lumber.

\begin{tabular}{|l|c|c|c|c|c|c|c|c|c|}
\hline Sampling time & $\mathbf{1}$ & $\mathbf{2}$ & $\mathbf{3}$ & $\mathbf{4}$ & $\mathbf{5}$ & $\mathbf{6}$ & $\mathbf{7}$ & $\mathbf{8}$ & $\mathbf{9}$ \\
\hline $\begin{array}{l}\text { Dry/wet bulb temperatures } \\
\left({ }^{\circ} \mathrm{C}\right)\end{array}$ & $101 / 97$ & $103 / 98$ & $105 / 97$ & $105 / 97$ & $105 / 97$ & $105 / 97$ & $105 / 97$ & $113 / 93$ & $115 / 90$ \\
\hline $\begin{array}{l}\text { Relative humidity } \\
(\%)\end{array}$ & 86.10 & 83.10 & 74.30 & 74.30 & 74.30 & 74.30 & 74.30 & 47.90 & 39.60 \\
\hline $\begin{array}{l}\text { Moisture content of lumber } \\
(\%)\end{array}$ & 106.16 & 103.00 & 99.00 & 93.00 & 80.28 & 71.93 & 53.72 & 22.43 & 11.98 \\
\hline
\end{tabular}

\section{RESULTS AND DISCUSSION}

The concentrations of formic acid, acetic acid, and methanol emitted during the high-temperature drying of Pinus Norway lumber were 215.6-748.2, 4148.8-16803.2, and 6381.9-15648.9 $\mathrm{mg} \cdot \mathrm{m}^{-3}$ (Tab. 2 ), respectively, which are significantly higher than the TWA and STEL values specified in relevant standards (Tab. 3). The results are consistent with concentrations of formic acid, acetic acid, and methanol emitted during the drying of Masson's pine wood at $120^{\circ} \mathrm{C}$. The gas emitted during the high-temperature drying of Pinus Norway lumber should be recycled and treated.

Tab. 2: Concentrations of formic acid, acetic acid, and methanol emitted during high-temperature drying.

\begin{tabular}{|l|c|c|c|c|c|c|c|c|c|}
\hline Sampling time & $\mathbf{1}$ & $\mathbf{2}$ & $\mathbf{3}$ & $\mathbf{4}$ & $\mathbf{5}$ & $\mathbf{6}$ & $\mathbf{7}$ & $\mathbf{8}$ & $\mathbf{9}$ \\
\hline $\begin{array}{l}\text { Formic acid } \\
\left(\mathrm{mg} \cdot \mathrm{m}^{-3}\right)\end{array}$ & 285.2 & 500.0 & 215.6 & 251.3 & 473.7 & 661.4 & 547.5 & 752.3 & 748.2 \\
\hline $\begin{array}{l}\text { Acetic acid } \\
\left(\mathrm{mg} \cdot \mathrm{m}^{-3}\right)\end{array}$ & 4481.6 & 5191.4 & 4148.8 & 4928.0 & 9381.5 & 11803.6 & 11636.2 & 12777.7 & 16803.2 \\
\hline $\begin{array}{l}\text { Methanol } \\
\left(\mathrm{mg} \cdot \mathrm{m}^{-3}\right)\end{array}$ & 7462.3 & 13059.7 & 15648.9 & 7719.5 & 6381.9 & 10897.5 & 12166.3 & 6505.6 & 10119.9 \\
\hline
\end{tabular}


Vol. 66 (3): 2021

Tab. 3: Concentration limits of formic acid, acetic acid, and methanol in the workplace.

\begin{tabular}{|l|c|c|c|c|c|c|}
\hline \multirow{2}{*}{ Standard } & \multicolumn{2}{|c|}{$\begin{array}{c}\text { Formic acid } \\
\left(\mathbf{m g}^{-3} \mathbf{3}\right.\end{array}$} & \multicolumn{2}{c|}{$\begin{array}{c}\text { Acetic acid } \\
\left(\mathbf{m g} \cdot \mathbf{m}^{-3}\right)\end{array}$} & \multicolumn{2}{c|}{$\begin{array}{c}\text { Methanol } \\
\left(\mathbf{m g}^{-3} \mathbf{m}^{-3}\right)\end{array}$} \\
\cline { 2 - 7 } & TWA & STEL & TWA & STEL & TWA & STEL \\
\hline GB Z-2002 & 10 & 20 & 10 & 20 & 25 & 50 \\
\hline New Zealand standard & 9.4 & 19 & 25 & 37 & 262 & 328 \\
\hline OSHA regulations & & & - & - & 260 & - \\
\hline TRGS 900 & & & 25 & - & - & - \\
\hline
\end{tabular}

Note: TWA (Time-weighted average), STEL (Short term exposure limit).

\section{Influences of drying temperature on the concentrations of acid and alcohol emissions}

The temperature of high-temperature drying ranged from 101 to $115^{\circ} \mathrm{C}$. The average concentrations of formic acid, acetic acid, and methanol of the third to the seventh samples dried at $105^{\circ} \mathrm{C}$ were calculated. As shown in Fig. 3, the concentrations of formic acid and acetic acid increased linearly with the drying temperature, and the determination coefficients (R2) were 0.9046 and 0.9621 , respectively. The drying temperature had no significant effect on the concentration of methanol emitted within the drying temperature range observed in this study. The concentration of emitted methanol ranged from 6381.9 to $15648.9 \mathrm{mg} \cdot \mathrm{m}^{-3}$ with an average of $9995.7 \mathrm{mg}^{-3}$.

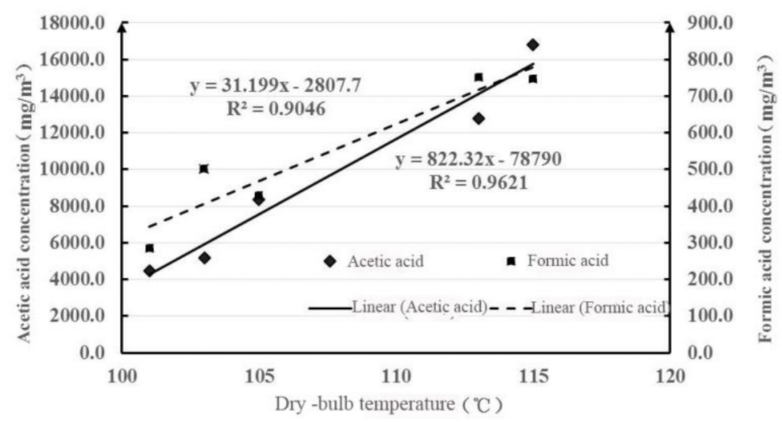

Fig. 3: Temperature vs. concentrations of formic acid and acetic acid.

When the drying temperature was less than $120^{\circ} \mathrm{C}$, the hemicelluloses and cellulose in wood had not yet reached the degradation stage, and lignin degradation was also rare. In other words, the degradation of the three components of wood produces negligible amounts of acids and alcohols. Hence, acids and alcohols may primarily be produced by the thermal decomposition of wood extracts, which is similar to the production mechanism of aldehyde substances (Schafer and Roffael 2000). At a constant drying temperature, the concentrations of acids and alcohols emitted from Norway pine lumber had been found to be significantly higher than those from plantation Chinese fir lumber. The VOC emission from high-temperature drying ofChinese firwas much higher than that from conventionaldrying. Because the drying time is long despite the low VOC release concentration at low temperature, there was little difference in the total VOC release between high-temperature and conventional drying (Ingram et al. 2000). The release rate of methanol, acetic acid and formic acid was significantly higher than that of aldehydes and terpenes (Long and Lu 2008). 
This can be attributed to the fact that the extract contents of benzyl alcohol in the Norway pine heartwood and sapwood were $30.01 \%$ and $7.31 \%$, respectively, while that of the plantation Chinese fir was $2.90 \%$ (Bao and Jiang 1998); additionally, the content of Norway pine lumber heartwood was high. Indeed, the extract content of radiate pine may be 10 times higher than that of Chinese fir.

\section{Influence of relative humidity on the concentrations of acid and alcohol emissions}

During the high-temperature drying of the timber samples, the relative humidity in the kiln ranged from $86.10 \%$ to $39.60 \%$. Similarly, the average concentrations of formic acid, acetic acid, and methanol of the third to seventh drying samples dried at $105^{\circ} \mathrm{C}$ were determined. As presented in Fig. 4, the concentrations of formic acid and acetic acid decreased linearly with the relative humidity, and the determination coefficients were 0.8632 and 0.9738 , respectively.

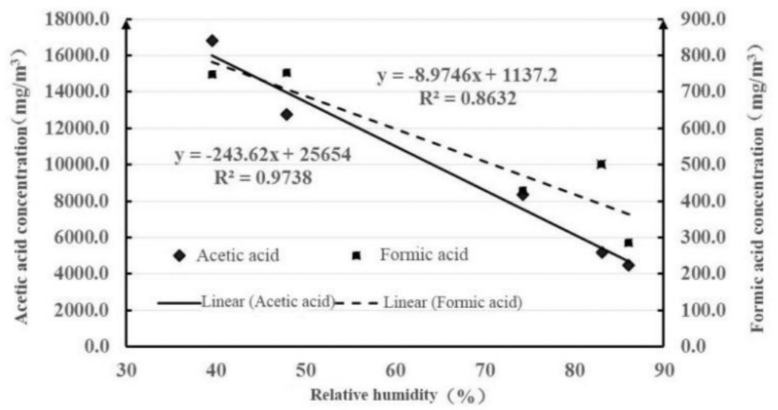

Fig. 4: Relative humidity vs. concentrations of formic acid and acetic acid.

The relative humidity had no significant effect on the concentration of methanol emitted. However, it was found that the relative humidity was inversely proportional to the drying temperature. Additionally, the concentrations of formic acid and acetic acid were inversely proportional to the relative humidity in the kiln, which may be attributed to the negative correlation between the relative humidity and temperature. It is also possible that, at a specific drying temperature, the concentrations of formic acid and acetic acid emitted remained unchanged, and the low relative humidity led to a low water vapor content, thus resulting in high concentrations of formic acid and acetic acid. Future research may focus on the effects of constant drying temperature and relative humidity on the concentrations of acid and alcohol emitted.

\section{Influence of moisture content of sawn timber on the concentrations of acid and alcohol emissions}

Some studies have shown that the volatilization amount of VOCs increases with the decrease of the final moisture content of wood, regardless of the drying temperature (Shmulsky and Ingram 2000). During the drying process, the moisture content of the lumber decreased from $106.16 \%$ to $11.98 \%$. As the moisture content of the lumber decreased, the concentrations of the formic acid and acetic acid emitted gradually increased, as shown in Fig. 5. The determination coefficients were 0.8521 and 0.9591 , respectively. At a drying temperature of $105^{\circ} \mathrm{C}$, as the drying proceeded, the moisture content of the lumber decreased from $99.00 \%$ to $53.72 \%$, while the concentrations of emitted formic acid and acetic acid increased linearly, as shown in Fig. 6. 


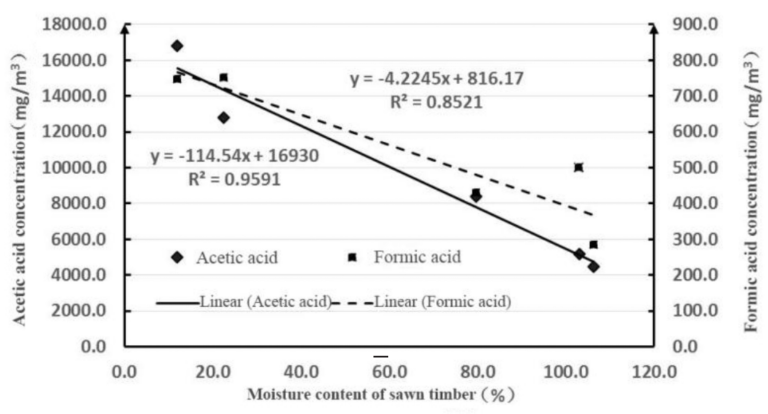

Fig. 5: Concentrations of formic acid and acetic acid vs. moisture content of lumber.

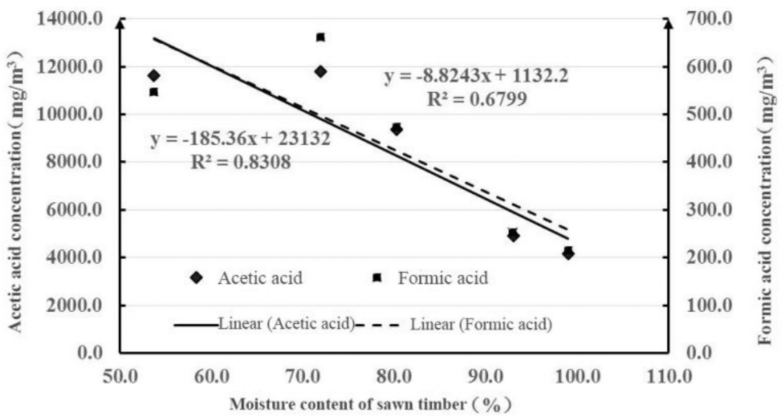

Fig. 6: Concentrations of formic acid and acetic acid vs. moisture content of lumber during drying at $105^{\circ} \mathrm{C}$.

The determination coefficients were 0.6799 and 0.8308 , respectively. In other words, the concentrations of formic acid and acetic acid emitted were inversely proportional to the moisture content of the lumber. However, the moisture content had no significant effect on the concentration of methanol emitted.

The dry-bulb temperature was also $105^{\circ} \mathrm{C}$. From the third to the seventh sampling, the moisture content of the lumber decreased as the drying time increased, resulting in increasing concentrations of formic acid and acetic acid. In contrast, the concentration of methanol emitted did not vary significantly with the moisture content of the lumber. Therefore, the influence of the moisture content of the lumber on the concentrations of acids and alcohols emitted was further confirmed.

\section{CONCLUSIONS}

The results of this study indicate that the concentrations of formic acid and acetic acid emissions are proportional to the drying temperature, while they are inversely proportional to the relative humidity and the moisture content of the lumber. The determination coefficients of all cases were found to be greater than 0.6799. In addition, the concentration of methanol 
emissions was found to be independent of the drying temperature, the relative humidity, and the moisture content of the lumber. The concentrations of formic acid, acetic acid, and methanol emissions exceeded the threshold values set by the China's national emission standards.

Hence, the recovery of exhausts during the high-temperature drying of wood is strongly recommended. Future studies should explore the effects of relative humidity on the concentrations of acid and alcohol emitted at a constant drying temperature. In addition, the emission mechanisms of acids and alcohols during high-temperature drying should be investigated.

\section{ACKNOWLEDGMENTS}

The author extends gratitude to Dr. Fan Zhou, Dr. Fu Zongying and Dr. Gao Xin for their support of this study. Parts of this work were financially supported by National Natural Science Foundation of China (Grant No. 31870536).

\section{REFERENCES}

1. Back, E.L., Allan, L.H., 2000: Pitch control, wood resin and deresination. Pp 77-101, Tappi Press, Atlanta, GA.

2. Bao, F.C., Jiang, Z.H., 1998: Wood properties of main tree species from plantation in China, Beijing: China forestry publishing house, $98 \mathrm{pp}$.

3. Sundqvist, B., 2004: Colour changes and acid formation in wood during heating. Luleå University of Technology 10: 1402-1544.

4. Dallons, V.C., Lamb, L.M., Peterson, M.R. , 1993: An alternate method for estimating VOC emissions from lumber dry kilns. Aiche Symposium. Series 90( 302) : 19-32.

5. Däumling, C., Brenske, K.R., Wilke, O., Horn, W., Jann, O., 2005: Health-related evaluation procedure of VOC and SVOC emissions from building products. A contribution to the European construction products directive. Gefahrstoffe Reinhaltung Der Luft 65(3): 90-92.

6. Englund, F., Nussbaum, R.M., 2000: Monoterpenes in Scots pine and Norway spruce and their emission during kiln drying. Holzforschung 54(5): 449-456.

7. Granström, K., 2003: Emissions of monoterpenes and VOCs during drying of sawdust in a spouted bed. Forest Products Journal 53(10): 48-55.

8. He, Z., Wang, Z., Qu, L., Qian, J., Yi, S., 2019: Gaseous decomposition products from wood degradation via thermo gravimetric and Fourier transform infrared analysis during thermal modification of beech and pine woods. Bioresources14(3): 6883-6894.

9. IARC, 1999: Acetaldehyde. IARC Summary and evaluation 71: 319.

10. Ingram, L., Shmulsky, R., Ashlie, T.D., Taylor, F.W., Templeton, M.C., 2000: The measurement of volatile organic emissions from drying southern pine lumber in a laboratory-scale kiln. Forest Products Journal 50(4): 91-94.

11. Pohleven. J., Burnard, M.D., Burnard, Kutnar, A., 2019: Volatile organic compounds emitted from untreated and thermally modified wood. A review. Wood and Fiber Science 51(3): 232-254.

12. Lavery, M.R., 1998: Hydrocarbon emissions from lumber dry kilns. M.S. thesis. Oregon St ate University, Corval-lis, 133 pp. 
13. Long, L., Liu, X.X., Zhang, Z.H.: 2007: Study on VOC emission during Eucalypt usurophylla drying. China Forest l'roducts Industry 34 (4): 8-13.

14. Long, L., Lu, X.X., 2008: VOC emissi nn from Chinese fir (Cunninghamia lanceolata) drying. Scientia Silvae Sinicae 44: 107-116

15. Long, L., 2012: Evaluate on VCC emission wood and wood products. China science publishing, Beijing, 157 pp.

16. Long, L., Lu, X.X., 2008: Release of orga nic volatiles during Chinese fir drying. Forestry science 01: 107-116.

17. Makowski, M., Ohlmeyer, M., Meier, D., ‘005: Long-term development of VOC emissions from OSB after hot-pressing. Holzforschu ig 48(5): 339-523.

18. Milota, M.R., 2000: Emissions from woor drying. Forest Products Journal 50(6): 10-20.

19. Risholm-Sundman,M., Lundgren,M., Vestin,E., Herder, P., 1998: Emissions of acetic acid and other volatile organic cnmpounds from different species of solid wood. Holz Als Roh-und Werkstolt 56: 125-129

20. Schafer, M., Roffael, E., 2000: 1)n the formaldehyde release of wood. Holz als Roh-und Werkstoff 58 (4): 259-264.

21. Shmulsky, R., Ingram, L.L., 2000: Empi ical prediction of VOC emissions from drying southern yellow pine lumber. Forest Produ sts Journal 50(6): 61-63.

22. Shmulsky, R., 2000: Influence of lumber dimension on voc emissions from kiln-drying loblolly pine lumber. Forest Products Jourr al 50(3): 63-66.

23. Tong, L.Z., 2009: Research status and devi:lopment trend of VOCs in wood drying process. Wood Processing Machinery 02: 38-41.

24. Wu, J., Milota, M. R. , 1999: Effect of $\mathrm{t}$ mmperature and humidity on total hydrocarbon emission from douglas-fir lumber. Forest F roducts Journal 49(6): 52-60.

25. Zhou, Y.D., Li, X.L., 2005: Comparison of high- temperature drying and conventional drying of Chinese fir lumber. Journal of Beijing Forestry University 27(Supp.): 18-21. 
Jiangyi Chu, Jinghui Jiang*, Yongdong Zhou

Chinese Academy Of Forestry

Research Institute Of Wood Industry

Wan Shou Shan, Haidian

Beijing

China

*Corresponding author: jiangjh@caf.ac.cn

Chusheng Qi

Beijing Forestry University

Materials Science And Technology

Shuangeing Road, Haidian

BeIjING

China 